\title{
Cerenkov-Specific Contrast Agents for Detection of pH In Vivo
}

\author{
Julie Czupryna, Alexander V. Kachur, Eric Blankemeyer, Anatoliy V. Popov, Alejandro D. Arroyo, Joel S. Karp, \\ and Edward J. Delikatny \\ Small Animal Imaging Facility, Department of Radiology, Perelman School of Medicine, University of Pennsylvania, Philadelphia, Pennsylvania
}

We report the design, testing, and in vivo application of $\mathrm{pH}$-sensitive contrast agents designed specifically for Cerenkov imaging. Radioisotopes used for PET emit photons via Cerenkov radiation. The multispectral emission of Cerenkov radiation allows for selective bandwidth quenching, in which a band of photons is quenched by absorption by a functional dye. Under acidic conditions, ${ }^{18} \mathrm{~F}$-labeled derivatives emit the full spectrum of Cerenkov light. Under basic conditions, the dyes change color and a wavelength-dependent quenching of Cerenkov emission is observed. Methods: Monoand di-18 F-labeled derivatives of phenolsulfonphthalein (phenol red) and meta-cresolsulfonphthalein (cresol purple) were synthesized by electrophilic fluorination. Cerenkov emission was measured at different wavelengths as a function of $\mathrm{pH}$ in vitro. Intramolecular response was measured in fluorinated probes and intermolecular quenching by mixing phenolphthalein with ${ }^{18} \mathrm{~F}-\mathrm{FDG}$. Monofluorocresol purple (MFCP) was tested in mice treated with acetazolamide to cause urinary alkalinization, and Cerenkov images were compared with PET images. Results: Fluorinated $\mathrm{pH}$ indicators were produced with radiochemical yields of $4 \%-11 \%$ at greater than $90 \%$ purity. Selective Cerenkov quenching was observed intramolecularly with difluorophenol red or monofluorocresol purple and intermolecularly in phenolphthalein ${ }^{18} \mathrm{~F}-\mathrm{FDG}$ mixtures. The probes were selectively quenched in the bandwidth closest to the indicator's absorption maximum $\left(\lambda_{\max }\right)$ at $\mathrm{pHs}$ above the indicator $\mathrm{pK}_{\mathrm{a}}$ (the negative logarithm of the acid dissociation constant). Addition of acid or base to the probes resulted in reversible switching from unquenched to quenched emission. In vivo, the bladders of acetazolamide-treated mice exhibited a wavelength-dependent quenching in Cerenkov emission, with the greatest reduction occurring near the $\lambda_{\max }$. Ratiometric imaging at 2 wavelengths showed significant decreases in Cerenkov emission at basic $\mathrm{pH}$ and allowed the estimation of absolute $\mathrm{pH}$ in vivo. Conclusion: We have created contrast agents that selectively quench photons emitted during Cerenkov radiation within a given bandwidth. In the presence of a functional dye, such as a pH indicator, this selective quenching allows for a functional determination of $\mathrm{pH}$ in vitro and in vivo. This method can be used to obtain functional information from radiolabeled probes using multimodal imaging. This approach allows for the imaging of nonfluorescent chromophores and is generalizable to any functional dye that absorbs at suitable wavelengths.

Key Words: Cerenkov imaging; ratiometric imaging; $\mathrm{pH}$ measurement; electrophilic fluorination; metacresol purple; phenolphthalein

J Nucl Med 2015; 56:483-488

DOI: 10.2967/jnumed.114.146605

Received Aug. 8, 2014; revision accepted Dec. 22, 2014

For correspondence or reprints contact: Edward J. Delikatny, 317 Anatomy

Chemistry Building, 3620 Hamilton Walk, Philadelphia, PA 19104.

E-mail: delikatn@mail.med.upenn.edu

Published online Feb. 5, 2015.

COPYRIGHT (C 2015 by the Society of Nuclear Medicine and Molecular Imaging, Inc.
C dality that detects photons emitted by radioactive particles during $\beta$ decay. Cerenkov radiation (CR) arises when charged particles exceed the speed of light when traveling through a dielectric medium and is the source of the blue light emitted by nuclear reactors. CR was described by Pavel Cerenkov, for which he won the 1958 Nobel Prize with Frank and Tamm $(1,2)$. However, the potential for CI was not recognized until 2009 when the first smallanimal study was published (3).

CI can be accomplished using standard optical imaging equipment, detecting the photons with a cooled, charge-coupled device camera. This method allows for high throughput (3-5 animals per scan in optical scanners), with scan times that are often less than 5 min $(4,5)$. In addition, any $\beta$-particle, positron, or electron can be imaged, allowing for CI of nuclei such as ${ }^{32} \mathrm{P}(6)$.

Most Cerenkov photons are in the visible range and as a result are subject to tissue absorption and scattering, limiting the depth of detection. Although more suited for small-animal applications, CI also has the potential for human imaging. Cerenkov studies of ${ }^{131} \mathrm{I}$ in human thyroid (7) and ${ }^{18} \mathrm{~F}-\mathrm{FDG}$ in positive lymph nodes from cancer patients $(8)$ have recently been published. Future human use will most likely be restricted to surface tumors or tumors accessible endoscopically $(9,10)$. Many breast tumors present close to the surface and the breast is compressible and has good optical properties, making this a potential target (11-14). Intraoperative use is also possible, and other groups are pursuing this approach (15-17).

Importantly, $\beta^{+}$decay leads to the generation of 2 types of photons, the high-energy 511-keV $\gamma$ rays released after positron annihilation and detectable by PET and the visible photons released as CR. These properties allow for the development of multimodal PET CI tracers (18-21). Current radiotracer methods detect primarily the location of the radioisotope; it is difficult to assess the probe metabolism directly. However, CI is an optical technique and the photons can be selectively quenched or transferred to higher wavelengths (22-24), allowing for the creation of contrast agents with which function can be measured optically while binding, kinetics, and location can be followed with PET.

This paper describes Cerenkov contrast agents (25-28) based on the concept of selective-bandwidth quenching (28). Cerenkov light is emitted continuously across the visible spectrum, with intensity proportional to the inverse square of the wavelength, $1 / \lambda^{2}$. A change in absorption by a functional chromophore, such as a fluorinated $\mathrm{pH}$ indicator becoming basic, reduces Cerenkov emission across a selective bandwidth, resulting in an attenuated signal.

We previously reported the synthesis of fluoroderivatives of the $\mathrm{pH}$ indicators phenolsulfonphthalein (phenol red [PR]) (26), 
meta-cresolsulfonphthalein (cresol purple [CP]) (27), and phenolphthalein (PP) (25). Here, we show that the ${ }^{18} \mathrm{~F}$ isotopomers can serve as noninvasive $\mathrm{pH}$ probes for $\mathrm{CI}$. We report ${ }^{18} \mathrm{~F}$-radiolabeling of $\mathrm{CP}$ and $\mathrm{PR}$ derivatives (Fig. 1) and in vitro testing and in vivo measurement of $\mathrm{pH}$ in a mouse model of urinary alkalinization. The principle of selective-bandwidth quenching is demonstrated intermolecularly using PP mixed with ${ }^{18} \mathrm{~F}$-FDG and intramolecularly using fluorinated PR and CP. The quenching is shown to be reversible and $\mathrm{pH}$-dependent. Finally ${ }^{18} \mathrm{~F}$-labeled $\mathrm{CP}$ is used to estimate $\mathrm{pH}$ in the bladders of mice treated with acetazolamide, a carbonic anhydrase inhibitor. Ratiometric imaging is used at different wavelengths to determine absolute $\mathrm{pH}$ values in vivo. These results provide methods for multispectral optical imaging of nonfluorescent molecules with the potential for dual measurement of function and location using radiolabeled probes.

\section{MATERIALS AND METHODS}

All reagents were purchased from Sigma-Aldrich unless otherwise stated. ${ }^{18} \mathrm{~F}-\mathrm{FDG}$ and ${ }^{18} \mathrm{~F}-\mathrm{NaF}$ were obtained from the Cyclotron Facility at the University of Pennsylvania.

\section{${ }^{18} \mathrm{~F}$ Labeling}

Labeling was performed using a custom-made electrophilic fluorination unit as previously described $(25-27) .{ }^{18} \mathrm{~F}-\mathrm{F}_{2}$ gas was prepared by the ${ }^{20} \mathrm{Ne}(d, \alpha){ }^{18} \mathrm{~F}$ reaction using an IBA $18 / 9$ Cyclone accelerator. ${ }^{18} \mathrm{~F}_{-} \mathrm{F}_{2}$ gas $(0.1 \%$ in Ne; Matheson Tri-Gas Inc.) with a total activity of 3.7-7.4 MBq (100-200 $\mu \mathrm{Ci})$ in $35 \mu \mathrm{mol}$ of ${ }^{19} \mathrm{~F}_{2}$ carrier was bubbled for $5 \mathrm{~min}$ through a freshly prepared solution of the equivalent amount of the monosodium salt of the indicator in glacial acetic acid $(2 \mathrm{mg} / \mathrm{mL})$. The mixture was evaporated under vacuum at $120^{\circ} \mathrm{C}$, redissolved in $2 \mathrm{~mL}$ of water, injected onto a semipreparative high-performance liquid chromatography (HPLC) column (Synergi, $4 \mu \mathrm{m}$ Hydro-RP 80 $\AA 10 \times 250 \mathrm{~mm}$; Phenomenex), and eluted with $25 \%$ ethanol-water buffer at $2 \mathrm{~mL} / \mathrm{min}$ with detection of radioactivity and absorption at $430 \mathrm{~nm}$. Fractions corresponding to fluorinated products were collected, evaporated to dryness, and redissolved in saline for further application. For PR, the average $(n=5)$ radiochemical yield was $4 \% \pm 1 \%$ for monofluorinated (MFPR), $7 \% \pm 1 \%$ for difluorinated $\mathrm{PR}$ (DFPR), and $1 \% \pm 0.5 \%$ for trifluorinated (TFPR) derivatives. For $\mathrm{CP}(n=9)$, the radiochemical yields were $9.6 \% \pm 1 \%$ for monofluorinated (MFCP [monofluorocresol purple]), $11 \% \pm 0.7 \%$ for difluorinated (DFCP), and $4.2 \% \pm 0.7 \%$ for trifluorinated (TFCP). In both cases, we were able to detect small amounts of tetrafluorinated

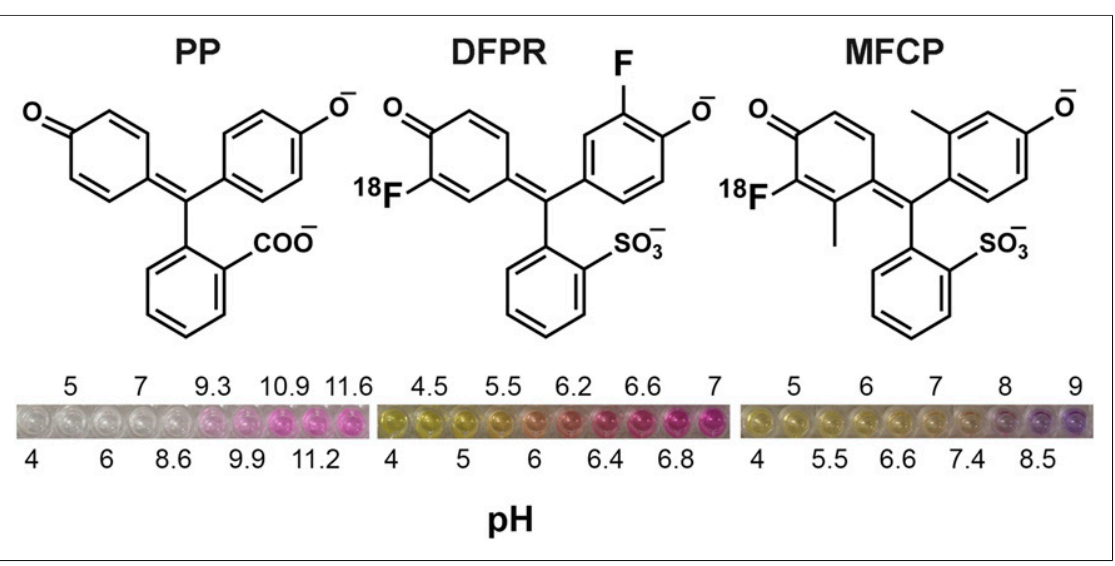

FIGURE 1. Chemical structures of pH indicators. (Left) PP. (Middle) DFPR. (Right) MFCP. $\mathrm{pH}$-dependent changes in indicator color are shown underneath. derivatives. The specific activity at the time of the experiment was $37-74 \mathrm{GBq}(1-2 \mathrm{Ci}) / \mathrm{mmol}$ for monofluorinated and $74-148 \mathrm{GBq}$ (2-4 Ci)/mmol for difluorinated derivatives, respectively. The purity of the probes was greater than $90 \%$ by analytic HPLC. Analytic HPLC for DFPR and nuclear magnetic resonance data for MFCP have been published $(26,27)$.

\section{In Vitro Cl}

Optical imaging was performed on an IVIS Lumina II (PerkinElmer) system. For open filter measurements, an exposure time of $30 \mathrm{~s}$ was used with large binning and an f/stop of 1 . For selective emission filter measurements, the exposure time was $60 \mathrm{~s}$. The Lumina has 4 emission filters with wavelengths 515-575, 575-650, 695-770, and 810-875 nm. The heater plate was set to room temperature to minimize evaporation. Black-walled 96-well plates (BD Biosciences) were filled with $200 \mu \mathrm{L}$ of probe at the indicated activities and concentrations. For $\mathrm{pH}$ imaging, the $\mathrm{pH}$ of the solution was adjusted using $0.1 \mathrm{M}$ acetate $(\mathrm{pH} 4-5.5)$, 2-morpholinoethane-1-sulfonate (MES) $(\mathrm{pH} 5.5-6.5)$, phosphate $(\mathrm{pH}$ 6.5-8), Trizma ( $\mathrm{pH} 8-9)$, borate $(\mathrm{pH} 9-10)$, or carbonate $(\mathrm{pH} \mathrm{10-11)}$ buffers. For switching experiments, the $\mathrm{pH}$ was adjusted using $1 \mathrm{M} \mathrm{HCl}$ or $\mathrm{NaOH}$. For phantom experiments, a $1-\mathrm{cm}^{3}$ acrylic phantom (Data Spectrum Corp.) was filled with ${ }^{18} \mathrm{~F}-\mathrm{FDG}$ and imaged under the same conditions. Image quantification was performed using Living Image software (PerkinElmer) by drawing regions of interest (ROIs) around each well and determining the radiance. A radioactive decay constant was applied to all data except for $\mathrm{pH}$-switching experiments to account for the time between plating and imaging.

\section{In Vitro A-PET Imaging}

After optical imaging, plates were centered in the field of view of the MOSAIC HP small-animal A-PET scanner (29) (Philips) and imaged statically for $15 \mathrm{~min}$. Images were reconstructed with a 3-dimensional row-action maximum-likelihood algorithm (30). Corrections for decay, scatter, and attenuation were applied using a ${ }^{137} \mathrm{Cs}$ source. Absolute quantification of activity from the dose calibrator was achieved with cross-calibration of phantom measurements.

\section{In Vivo CI}

All experiments were approved by our Institutional Animal Care and Use Committee. For ${ }^{18}$ F-FDG, 4- to 6-wk-old nude mice (NCI) received approximately $16.095 \mathrm{MBq}(435 \mu \mathrm{Ci})$ of ${ }^{18} \mathrm{~F}-\mathrm{FDG}$ intravenously via the tail. For $\mathrm{pH}$ experiments, mice received $160 \mathrm{mg}$ of acetazolamide per $\mathrm{kg}$ (X-Gen Pharmaceuticals) in saline or saline intraperitoneally for $5 \mathrm{~d}$. On day 5 , urine was collected and $\mathrm{pH}$ determined using an Accumet $\mathrm{pH}$ meter. Four hours later, mice were injected intravenously with approximately $14.8 \mathrm{MBq}(400 \mu \mathrm{Ci})$ of ${ }^{18} \mathrm{~F}-\mathrm{MFCP}$. Thirty minutes later, mice were imaged with the IVIS Lumina II under $1.5 \%$ isoflurane/ oxygen anesthesia using the following parameters: open filter - exposure time, $1 \mathrm{~min}$; binning, large; f/stop, 1; and selective emission filters - exposure time, $5 \mathrm{~min}$. Image quantification was performed by drawing ROIs and determining the radiance. Optical data were corrected for radioactive decay to account for loss in activity and then normalized to the A-PET images by dividing the radiance by the PET counts in the same ROI to account for injection efficiency.

\section{In Vivo A-PET Imaging}

Subsequent to ${ }^{18} \mathrm{~F}-\mathrm{MFCP}$ injection, each mouse was imaged statically in the MOSAIC HP small-animal PET scanner for $15 \mathrm{~min}$. The 


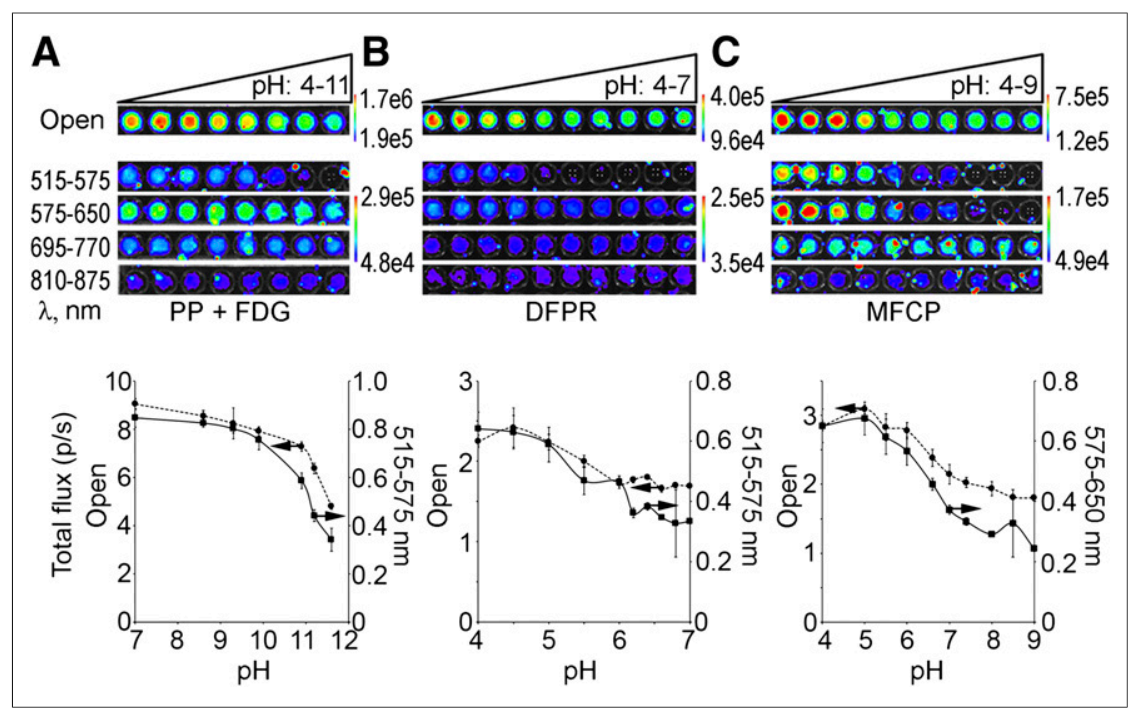

FIGURE 2. Inter- and intramolecular quenching of CR. (A) PP (25 mM) was adjusted to $\mathrm{pH} 4-11$, mixed with $3.7 \mathrm{MBq}(100 \mu \mathrm{Ci})$ of ${ }^{18} \mathrm{~F}-\mathrm{FDG}$, and imaged using all filters on IVIS Lumina II. (Top) Images of plate are shown. (Bottom) Quantifications of total flux normalized to A-PET counts for open filter (dashed line) and optimal-quenching 515- to 575-nm filter (solid line) are shown. (B) $\left.\left.{ }^{18 F-D F P R ~(3.7 ~ M B q ~[100 ~} \mu \mathrm{Ci}\right] ; 25 \mathrm{nmol}\right)$ adjusted to $\mathrm{pH} 4-7$, with open and 515- to 575-nm filter quantification shown. (C) ${ }^{18} \mathrm{~F}-\mathrm{MFCP}(5.18 \mathrm{MBq}[140 \mu \mathrm{Ci}] ; 0 \mathrm{nmol})$ adjusted to $\mathrm{pH} 4-9$, with open and $575-$ to $650-\mathrm{nm}$ filters. For each $\mathrm{pH}$ indicator, filtered images were set to same scale. For all experiments, $n=3$.

images were reconstructed as described above using a voxel size of $0.5 \times 0.5 \times 0.5 \mathrm{~mm}$. Decay, scatter, and attenuation correction were applied. All activity is assumed to be inside the mouse for the purposes of calculation of activity concentration because we monitored the excreted activity from the mouse.

\section{RESULTS}

Initial experiments were performed to characterize Cerenkov emission in vitro and in vivo using different emission filters (supplemental information; supplemental materials are available at http://jnm.snmjournals.org). A strong linear correlation was observed between optical and A-PET signals (Supplemental Fig. 1). Selective emission filters showed that the bulk of the photons were emitted at lower wavelengths (515-575 and 575-650 nm, Supplemental Figs. 2 and 3B), and the emission spectrum followed the expected $1 / \lambda^{2}$ dependence (Supplemental Fig. 3B). Importantly, the emission spectrum exhibited different characteristics when $\mathrm{CR}$ was examined in vivo. Mice imaged after administration of ${ }^{18}$ F-FDG showed a marked decrease in Cerenkov intensity using the lowest-wavelength $(515-575 \mathrm{~nm})$ filter, due to attenuation and scattering by tissue at these wavelengths (Supplemental Fig. 4).

To design Cerenkov-specific contrast agents, intermolecular quenching of CR was first measured using PP, which is colorless when acidic $\left(\lambda_{\text {acidic }}=276 \mathrm{~nm}\right)$ and fuchsia when basic (the negative logarithm of the acid dissociation constant $\left[\mathrm{pK}_{\mathrm{a}}\right]=9.8, \lambda_{\text {basic }}=553 \mathrm{~nm}$, Fig. 1). Mixing $3.7 \mathrm{MBq}(100 \mu \mathrm{Ci})$ of ${ }^{18} \mathrm{~F}-\mathrm{FDG}$ with $25 \mathrm{mM}$ $\mathrm{PP}$ led to a $\mathrm{pH}$-dependent quenching of $\mathrm{CR}$ when the open, 515- to 575-, and 575- to 650$\mathrm{nm}$ filters were used (Fig. 2A). Quenching was less pronounced in the remaining filters, and the signal was much lower in the 810- to 875-nm range, reflecting the reduced photon emission at these wavelengths.

To demonstrate intramolecular quenching, ${ }^{18} \mathrm{~F}$-labeled derivatives of a series of $\mathrm{pH}$ indicators were synthesized (25-27). The properties of 10 of these indicators are presented in Table 1. For further investigation, we first selected DFPR (Fig. 1), which exhibits a yellow (acidic) to red (basic) transition. ${ }^{18} \mathrm{~F}-\mathrm{DFPR}\left(\mathrm{pK}_{\mathrm{a}}=6.4, \lambda_{\text {acidic }}=428 \mathrm{~nm}, \lambda_{\text {basic }}=\right.$ $570 \mathrm{~nm}$ ) was examined in the $\mathrm{pH}$ range $4-7$. Figure $2 \mathrm{~B}$ shows that selective CR quenching occurred at basic $\mathrm{pH}$ when the open, 515to 575-, and 575- to 650-nm filters were used, with the greatest quenching observed near $\lambda_{\text {basic }}$.

${ }^{18} \mathrm{~F}$-DFPR exhibited less of a pH-dependent effect than PP, and the quenching plateaued at a $\mathrm{pH}$ greater than 6 , leading to little overall change in the Cerenkov emission. Thus, we examined ${ }^{18} \mathrm{~F}-$ $\operatorname{MFCP}\left(\mathrm{pK}_{\mathrm{a}}=7.5, \lambda_{\text {acidic }}=440 \mathrm{~nm}, \lambda_{\text {basic }}=582 \mathrm{~nm}\right.$, Fig. 1), which is yellow when acidic and purple under basic conditions. As shown in Figure 2C, ${ }^{18} \mathrm{~F}-\mathrm{MFCP}$ quenches Cerenkov emission in the open, 515- to 575-, and 575- to 650-nm filters as $\mathrm{pH}$ increases. Quantification of the images is shown in the lower panels of Figures $2 \mathrm{~A}-2 \mathrm{C}$. Only the open and $515-$ to $575-\mathrm{nm}\left(\mathrm{PP}+{ }^{18} \mathrm{~F}-\right.$ FDG, ${ }^{18} \mathrm{~F}$-DFPR) or 575- to 650 -nm $\left({ }^{18} \mathrm{~F}-\mathrm{MFCP}\right)$ filters are shown because they exhibited the greatest change in $\mathrm{CR}$ over the $\mathrm{pH}$ range. ${ }^{18} \mathrm{~F}-\mathrm{MFCP}$ shows the greatest $\mathrm{pH}$-dependent changes in

TABLE 1

Properties of Parent and F-Labeled $\mathrm{pH}$ Indicators

\begin{tabular}{|c|c|c|c|c|c|c|}
\hline \multirow[b]{2}{*}{ Indicator name } & \multicolumn{2}{|c|}{ Parent compound } & \multicolumn{2}{|c|}{ Monofluorinated } & \multicolumn{2}{|c|}{ Difluorinated } \\
\hline & $\mathrm{pK}_{\mathrm{a}}$ & $\lambda_{\max }$ & $\mathrm{pK}_{\mathrm{a}}$ & $\lambda_{\max }$ & $\mathrm{pK}_{\mathrm{a}}$ & $\lambda_{\max }$ \\
\hline Phenol red & 7.9 & 558 & 7.3 & 564 & 6.4 & 570 \\
\hline Cresol red & 8.2 & 572 & 7.6 & 576 & 6.8 & 582 \\
\hline Cresol purple & 8.3 & 578 & 7.5 & 582 & 7.0 & 590 \\
\hline Phenolphthalein & 9.7 & 553 & 9.3 & 558 & 8.7 & 564 \\
\hline Naptholphthalein & 7.8 & 653 & 7.7 & 659 & 7.2 & 665 \\
\hline
\end{tabular}

$\mathrm{pK}_{\mathrm{a}}=$ negative logarithm of acid dissociation constant (unitless); $\lambda_{\max }=$ absorbance maximum of basic form in $\mathrm{nm}$. 
Cerenkov emission (2.7- as compared with 1.9-fold for ${ }^{18} \mathrm{~F}-\mathrm{DFPR}$ and 2.5-fold for intermolecular PP), with a $\mathrm{pK}_{\mathrm{a}}$ relevant for in vivo studies. Quantification of the remaining filter sets is shown in Supplemental Figure 5.

Intermolecular quenching of CR was shown to be switchable by adding acid or base to wells containing $25 \mathrm{mM}$ PP and $3.7 \mathrm{MBq}$ $(100 \mu \mathrm{Ci})$ of ${ }^{18} \mathrm{~F}-\mathrm{FDG}$ (Fig. 3A). Intramolecular switching was also observable with either of the fluorinated indicators, ${ }^{18} \mathrm{~F}-\mathrm{MFCP}$ of ${ }^{18}$ F-DFPR (Figs. 3B-3C). Quantification of these images (Figs. $3 \mathrm{~A}-3 \mathrm{C}$, lower panels) demonstrates that for PP, the greatest change was seen using the open filter or filters at wavelengths closest to the indicator's absorption maximum $\left(\lambda_{\max }\right)(515-575$ and $575-650 \mathrm{~nm}$; Fig. 3A). Both ${ }^{18}$ F-DFPR and ${ }^{18} \mathrm{~F}-\mathrm{MFCP}$ exhibited similar characteristics (Figs. 3B and 3C), with maximum switching observed near the $\lambda_{\max }$ of the chromophores.

To test ${ }^{18} \mathrm{~F}-\mathrm{MFCP}$ in vivo, nude mice were treated with acetazolamide $(160 \mathrm{mg} / \mathrm{kg}$, intraperitoneally) or phosphate-buffered saline (PBS) for $5 \mathrm{~d}$. On day 6, mouse urine was collected and $\mathrm{pH}$ measured. The urine of PBS-treated mice had a $\mathrm{pH}$ of $6.2 \pm$ $0.1(n=3)$, whereas acetazolamide-treated mice had a urine $\mathrm{pH}$ of $8.5 \pm 0.2(n=3)$. Mice were administered ${ }^{18} \mathrm{~F}-\mathrm{MFCP}$ and imaged optically $30 \mathrm{~min}$ later, followed by A-PET imaging. The A-PET images show probe accumulation in the gallbladder, liver, intestine, and bladder (Fig. 4A). When normalized to dose injected per animal, a difference of less than 5\% was observed in the average standardized uptake value from the bladders of PBS- and acetazolamide-treated mice ( $1.443 \pm 0.405$ vs. $1.444 \pm 0.471$, respectively). Optical images taken using the open filter show a brighter signal in the PBS-treated mouse bladder than the acetazolamide-treated animal (Fig. 4B). When the remaining filters were used, the greatest difference between
PBS- and acetazolamide-treated animals occurred using the 575- to 650-nm filter (Fig. 4C), consistent with the $\lambda_{\text {basic }}$ equaling 582 $\mathrm{nm}$ for ${ }^{18} \mathrm{~F}-\mathrm{MFCP}$. The images were quantified by normalizing the average radiance to the mean PET counts and corrected for decay due to the injection time of the tracer. Open filter images showed a decrease in acetazolamide-treated mice just outside the level of significance (Fig. 5A, $P=0.07$ ). Quantification of the selective filter sets (Fig. 5B) showed nonsignificant decreases, with the greatest difference observed again using the 575- to 650-nm filter. Emissions at wavelengths outside the absorbance range of MFCP were not affected by acetazolamide treatment.

Ratiometric calculations were performed by taking emission for each filter relative to $810-875 \mathrm{~nm}$, which was invariant to $\mathrm{pH}$ changes and for which the greatest light penetration was expected. The ratiometric calculation showed a significant difference between acetazolamide- and PBS-treated mice for the 575- to 650-nm ( $P=$ 0.01 , Student $t$ test $)$ and 695- to 770-nm $(P=0.02)$, but not for the 515- to $575-\mathrm{nm}$, filters $(P=0.47$, Fig. $5 \mathrm{C})$. A ratiometric $\mathrm{pH}$ response curve was created from in vitro ${ }^{18} \mathrm{~F}-\mathrm{MFCP}$ data using Cerenkov emission at $575-650 \mathrm{~nm}$, for which the greatest $\mathrm{pH}$ response was observed, relative to $810-875 \mathrm{~nm}$ (Fig. 5D). A fit to a sigmoidal curve gave a $\mathrm{pK}_{\mathrm{a}}$ of 6.25 and an $R^{2}$ of 0.956 . The in vivo ratios from control and acetazolamide-treated mice were plotted against ex vivo urine $\mathrm{pH}$. The in vivo ratios predicted absolute $\mathrm{pH}$ with reasonable accuracy, although the values tended to lie above the curve (Fig. 5D).

\section{DISCUSSION}

In this paper, we describe the synthesis, in vitro characterization, and in vivo testing of ${ }^{18} \mathrm{~F}$-labeled $\mathrm{pH}$ indicators designed to exploit the characteristics of CR. The multispectral nature of Cerenkov emission allows for selective quenching of a band of photons by a functional chromophore that is used to report on $\mathrm{pH}$.

The biologic manifestations of $\mathrm{pH}$ modulation are numerous and significant. From reduced $\mathrm{pH}$ in lysosomes (31) to reduced $\mathrm{pH}$ in the extracellular space of tumors (32, 33), multimodal in vivo $\mathrm{pH}$ sensors could have considerable impact on the field of molecular imaging. Our approach differs from other methods of measuring $\mathrm{pH}$ (34) in that we are directly monitoring the absorption of colorimetric $\mathrm{pH}$ indicators, which is a standard method of $\mathrm{pH}$ determination. Although optical imaging agents that emit in the near-infrared range are preferred for in vivo imaging (35), the bulk of the Cerenkov signal is located near the blue end of the visible spectrum $(3,36)$. To create a balance between available signal and adequate penetration of light through tissue, $\mathrm{pH}$-responsive $\mathrm{CI}$ probes were developed to exhibit selectivebandwidth quenching in the 575- to 650-nm range. Our initial mouse studies showed that although we could detect ${ }^{18}$ F-FDG in nude mice using all of the emission filters, the Cerenkov emission using the 515- to 


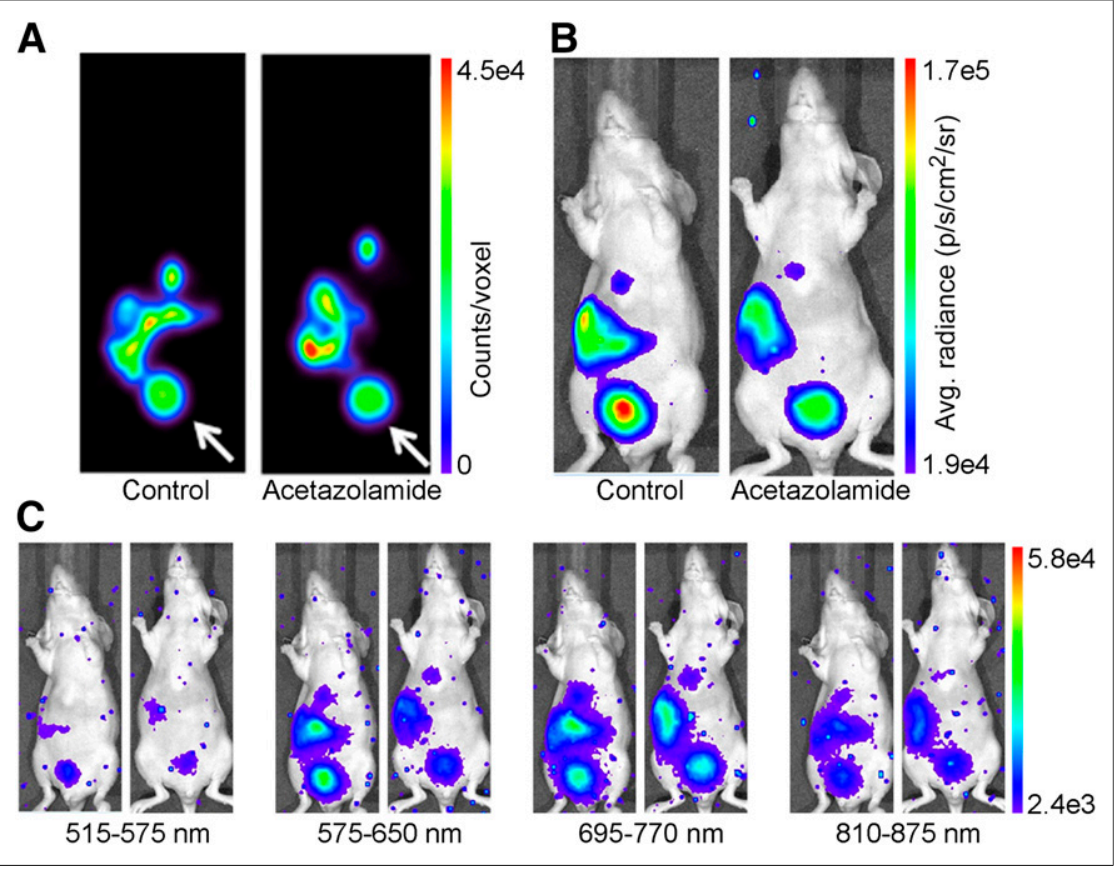

FIGURE 4. In vivo imaging of Cerenkov quenching. Mice were treated with either saline or acetazolamide $\left(160 \mathrm{mg} / \mathrm{kg}\right.$ ) for $5 \mathrm{~d}$ before imaging with ${ }^{18} \mathrm{~F}-\mathrm{MFCP}$. (A) A-PET images of single coronal slice $(0.5-\mathrm{mm}$ thick) through center of mouse in control and acetazolamide-treated mice show ${ }^{18} \mathrm{~F}-\mathrm{MFCP}$ accumulation in bladder (white arrow), gallbladder, liver, and intestine. Optical images of same mice were acquired using open filter (B) and 4 emission filters (C). Avg. = average.
The common $\mathrm{pH}$ indicator, $\mathrm{PP}\left(\lambda_{\max }=\right.$ $553 \mathrm{~nm}$ ), was used to demonstrate intermolecular CR quenching. Wavelength-dependent quenching of $\mathrm{CR}$ was observed to be the most effective at $515-575 \mathrm{~nm}$ in the $\mathrm{pH}$ range $4-1$, with relatively little quenching seen outside the absorption range of PP. However, PP could not quench CR in our target bandwidth of $575-650 \mathrm{~nm}$, and the $\mathrm{pH}$ necessary for quenching $(>9)$ was not biologically relevant.

Intermolecular quenching of $\mathrm{CR}$ has also been shown in vivo using nanoparticles (37). However, intramolecular quenching would ultimately be more useful as it would require a single contrast injection. As a result ${ }^{18} \mathrm{~F}$ DFPR, a derivative of the $\mathrm{pH}$ indicator commonly used in cell culture, was synthesized. Quenching could be now observed in both the 515- to 575-nm filter and the target bandwidth of 575-650 nm. Although ${ }^{18}$ F-DFPR could effectively quench $\mathrm{CR}$, a relatively small difference in emission was observed between acidic and basic forms. Thus, we synthesized ${ }^{18} \mathrm{~F}-\mathrm{MFCP}$ and found that it outperformed ${ }^{18} \mathrm{~F}-\mathrm{DFPR}$ and PP in the magnitude of quenching in the target bandwidth.

In addition to selectively quenching a targeted bandwidth, it was critical that 575-nm filter was markedly lower than the 575- to $650-\mathrm{nm}$ filter, due to photon absorption and scattering at shorter wavelengths.

the sensors be switchable to accurately reflect the surrounding environment. The sequential addition of base and acid to ${ }^{18} \mathrm{~F}$ MFCP led to stepwise quenching and restoration of CI, respectively. Although ${ }^{18} \mathrm{~F}-\mathrm{MFCP}$ exhibited the highest potential as an in vivo probe, we also investigated PP $+{ }^{18} \mathrm{~F}$-FDG and ${ }^{18} \mathrm{~F}$ DFPR and found that they were both capable of switching. These results indicate that it is possible to rapidly monitor $\mathrm{pH}$ changes dynamically in the extracellular tumor space of the tumor microenvironment.

In vivo experiments were performed using ${ }^{18} \mathrm{~F}-\mathrm{MFCP}$ in a mouse model of urinary alkalization. Acetazolamide is a carbonic anhydrase inhibitor that is used to treat metabolic and respiratory alkalosis. In doing so, it causes blood acidification and urinary alkalization. The latter property, along with the collection of smallmolecule radiopharmaceuticals in urine due to renal clearance, provided a model to test how well ${ }^{18} \mathrm{~F}$-MFCP reports on in vivo $\mathrm{pH}$. Mouse urine $\mathrm{pH}$ was measured to be $6.2 \pm 0.1$ in controls and $8.5 \pm 0.2$ in acetazolamide-treated animals using a $\mathrm{pH}$ meter. Optical images of the bladder obtained after ${ }^{18} \mathrm{~F}-\mathrm{MFCP}$ administration showed a clear difference in CR output between the 2 experimental conditions whereas no difference in PET signal was seen. Control animals exhibited a brighter signal than acetazolamide-treated animals,

FIGURE 5. Quantification of in vivo Cerenkov images. Average radiance from bladder using open filter (A), 4 selective filters (B), and ratio of emission at each filter relative to $810-875 \mathrm{~nm}(\mathrm{C})$. *Significant, $P<0.05$, Student $t$ test. (D) Ratiometric $\mathrm{pH}$ determination. $\bigcirc=$ ratio of Cerenkov emission at $(575-650 \mathrm{~nm}) /(810-875 \mathrm{~nm})$ for in vitro ${ }^{18} \mathrm{~F}-\mathrm{MFCP}$ (data from Fig. $2 \mathrm{C}$ ); solid line = fit to sigmoidal curve and gives $\mathrm{pK}_{\mathrm{a}}$ of 6.25 , similar to 6.4 determined by open filter data; $\bullet=$ Cerenkov emission from control mice plotted against actual urine $\mathrm{pH}$; $\mathbf{=}=$ Cerenkov emission from acetazolamidetreated mice plotted against actual urine $\mathrm{pH}$. avg. = average; Norm. = normal. 
with the greatest difference seen in the open and 575- to 650-nm filter images. After imaging, expelled urine from acetazolamide-treated animals was dark purple (not shown), indicating further that the urine was basic as measured by ${ }^{18} \mathrm{~F}-\mathrm{MFCP}$.

When ROIs around the bladder were quantified, the differences were not significant unless ratios were taken relative to the invariant signal at $810-875 \mathrm{~nm}$. With the ratiometric method, it is possible for ${ }^{18} \mathrm{~F}$-MFCP to report on absolute $\mathrm{pH}$. We constructed a normalized $\mathrm{pH}$ response curve using in vitro ${ }^{18} \mathrm{~F}-\mathrm{MFCP}$ data by taking the ratio of emission at $575-650$ to $810-875 \mathrm{~nm}$. When the same ratios from the control and acetazolamide-treated mice were plotted on the $\mathrm{pH}$ response curve, the $\mathrm{CR}$ values correlated well, although they tended to lie above the curve and underestimate the actual $\mathrm{pH}$. This effect may arise from scattering or absorption of light at different wavelengths, which would not contribute to the in vitro data. The $\mathrm{pK}_{\mathrm{a}}$ for ${ }^{18} \mathrm{~F}-\mathrm{MFCP}$ as determined by Cerenkov emission in vitro (6.2) is lower than the $\mathrm{pK}_{\mathrm{a}}$ measured using absorption (7.2). The reason for this is uncertain, although similar effects were observed for ${ }^{18} \mathrm{~F}$-DFCR and ${ }^{18} \mathrm{~F}-\mathrm{PP}$ mixed with ${ }^{18} \mathrm{~F}$-FDG.

\section{CONCLUSION}

We have demonstrated the ability to image $\mathrm{pH}$ using selectivebandwidth quenching of Cerenkov-specific contrast agents. In vivo results show that ${ }^{18} \mathrm{~F}-\mathrm{MFCP}$ is capable of reporting $\mathrm{pH}$ in animal models, opening several possibilities because it allows for the direct imaging of visible chromophores. The concept of selectivebandwidth quenching is generalizable to other dyes that alter their absorption in response to chemical or physiologic stimuli and that absorb at wavelengths appropriate for CI. These concepts define a method for the functional imaging of nonfluorescent chromophores that could be used in conjunction with PET.

\section{DISCLOSURE}

The costs of publication of this article were defrayed in part by the payment of page charges. Therefore, and solely to indicate this fact, this article is hereby marked "advertisement" in accordance with 18 USC section 1734. This study was supported by R01 EB018645-01 and by a Transdisciplinary Awards Program in Translational Medicine and Therapeutics / Translational Biomedical Imaging Core (TAPITMAT-TBIC) pilot grant through UL 1RR024134. No other potential conflict of interest relevant to this article was reported.

\section{REFERENCES}

1. Tamm IE. General characteristics of Vavilov-Cherenkov radiation. Science. 1960;131:206-210.

2. Cherenkov PA. Radiation from high-speed particles. Science. 1960;131:136-142.

3. Robertson R, Germanos MS, Li C, Mitchell GS, Cherry SR, Silva MD. Optical imaging of Cerenkov light generation from positron-emitting radiotracers. Phys Med Biol. 2009;54:N355-N365.

4. Liu H, Ren G, Miao Z, et al. Molecular optical imaging with radioactive probes. PLOS ONE. 2010;5:e9470.

5. Aweda TA, Eskandari V, Kukis DL, et al. New covalent capture probes for imaging and therapy, based on a combination of binding affinity and disulfide bond formation. Bioconjug Chem. 2011;22:1479-1483.

6. Spinelli AE, Kuo C, Rice BW, et al. Multispectral Cerenkov luminescence tomography for small animal optical imaging. Opt Express. 2011;19:12605-12618.

7. Spinelli AE, Ferdeghini M, Cavedon C, et al. First human Cerenkography. J Biomed Opt. 2013;18:20502-1-020502-3.

8. Thorek DL, Riedl C, Grimm J. Clinical Cerenkov luminescence imaging of ${ }^{18}$ F-FDG. J Nucl Med. 2014;55:95-98.

9. Zhang JG, Liu HF. Functional imaging and endoscopy. World J Gastroenterol. 2011;17:4277-4282.
10. Kothapalli SR, Liu H, Liao JC, Cheng Z, Gambhir SS. Endoscopic imaging of Cerenkov luminescence. Biomed Opt Express. 2012;3:1215-1225.

11. Corlu A, Choe R, Durduran T, et al. Three-dimensional in vivo fluorescence diffuse optical tomography of breast cancer in humans. Opt Express. 2007; 15:6696-6716.

12. Durduran T, Choe R, Yu G, et al. Diffuse optical measurement of blood flow in breast tumors. Opt Lett. 2005;30:2915-2917.

13. Tromberg BJ, Pogue BW, Paulsen KD, Yodh AG, Boas DA, Cerussi AE. Assessing the future of diffuse optical imaging technologies for breast cancer management. Med Phys. 2008;35:2443-2451.

14. Boverman G, Fang Q, Carp SA, et al. Spatio-temporal imaging of the hemoglobin in the compressed breast with diffuse optical tomography. Phys Med Biol. 2007;52:3619-3641.

15. Liu $\mathrm{H}$, Carpenter $\mathrm{CM}$, Jiang $\mathrm{H}$, et al. Intraoperative imaging of tumors using Cerenkov luminescence endoscopy: a feasibility experimental study. J Nucl Med. 2012;53:1579-1584.

16. Holland JP, Normand G, Ruggiero A, Lewis JS, Grimm J. Intraoperative imaging of positron emission tomographic radiotracers using Cerenkov luminescence emissions. Mol Imaging. 2011;10:177-186, 1-3.

17. Thorek DL, Abou DS, Beattie BJ, et al. Positron lymphography: multimodal, high-resolution, dynamic mapping and resection of lymph nodes after intradermal injection of ${ }^{18}$ F-FDG. J Nucl Med. 2012;53:1438-1445.

18. Robertson R, Germanos MS, Manfredi MG, Smith PG, Silva MD. Multimodal imaging with ${ }^{18} \mathrm{~F}$-FDG PET and Cerenkov luminescence imaging after MLN4924 treatment in a human lymphoma xenograft model. J Nucl Med. 2011;52:1764-1769.

19. Ruggiero A, Holland JP, Lewis JS, Grimm J. Cerenkov luminescence imaging of medical isotopes. J Nucl Med. 2010;51:1123-1130.

20. Li C, Mitchell GS, Cherry SR. Cerenkov luminescence tomography for smallanimal imaging. Opt Lett. 2010;35:1109-1111.

21. Natarajan A, Habte F, Liu H, et al. Evaluation of Zr-rituximab tracer by Cerenkov luminescence imaging and correlation with PET in a humanized transgenic mouse model to image NHL. Mol Imaging Biol. 2013;15:468475 .

22. Dothager RS, Goiffon RJ, Jackson E, Harpstrite S, Piwnica-Worms D. Cerenkov radiation energy transfer (CRET) imaging: a novel method for optical imaging of PET isotopes in biological systems. PLoS ONE. 2010;5:e13300.

23. Kotagiri N, Niedzwiedzki DM, Ohara K, Achilefu S. Activatable probes based on distance-dependent luminescence associated with Cerenkov radiation. Angew Chem Int Ed Engl. 2013;52:7756-7760.

24. Axelsson J, Davis SC, Gladstone DJ, Pogue BW. Cerenkov emission induced by external beam radiation stimulates molecular fluorescence. Med Phys. 2011; 38:4127-4132.

25. Kachur AV, Popov AA, Delikatny EJ, Karp JS, Popov AV. Synthesis of ${ }^{18} \mathrm{~F}-$ labeled phenolphthalein and naphtholphthalein. J Fluorine Chem. 2013;151:1-6.

26. Kachur AV, Popov AV, Karp JS, Delikatny EJ. Direct fluorination of phenolsulfonphthalein: a method for synthesis of positron-emitting indicators for in vivo pH measurement. Cell Biochem Biophys. 2013;66:1-5.

27. Kachur AV, Sardelis D, Bentzley C, Popov AV, Delikatny EJ, Karp JS. Synthesis and characterization of fluorinated derivatives of cresolsulfonphthalein. $J$ Fluorine Chem. 2013;145:112-117.

28. Czupryna J, Kachur AV, Blankemeyer E, Popov AV, Karp JS, Delikatny EJ. In vivo $\mathrm{pH}$ detection using switchable ${ }^{18} \mathrm{~F}$ labeled Cerenkov probes [abstract]. J Nucl Med. 2012;53(suppl 1):73.

29. Surti S, Karp JS, Perkins AE, et al. Imaging performance of A-PET: a small animal PET camera. IEEE Trans Med Imaging. 2005;24:844-852.

30. Daube-Witherspoon ME, Matej S, Karp JS, Lewitt RM. Application of the row action maximum likelihood algorithm with spherical basis functions to clinical PET imaging. IEEE Trans Nucl Sci. 2001;48:24-30.

31. Mindell JA. Lysosomal acidification mechanisms. Annu Rev Physiol. 2012; 74:69-86.

32. Robey IF, Baggett BK, Kirkpatrick ND, et al. Bicarbonate increases tumor $\mathrm{pH}$ and inhibits spontaneous metastases. Cancer Res. 2009;69:2260-2268.

33. Hashim AI, Zhang X, Wojtkowiak JW, Martinez GV, Gillies RJ. Imaging pH and metastasis. NMR Biomed. 2011;24:582-591.

34. Zhang $\mathrm{X}$, Lin Y, Gillies RJ. Tumor $\mathrm{pH}$ and its measurement. J Nucl Med. 2010;51:1167-1170.

35. Ntziachristos V, Bremer C, Weissleder R. Fluorescence imaging with nearinfrared light: new technological advances that enable in vivo molecular imaging. Eur Radiol. 2003;13:195-208.

36. Park JC, Il An G, Park SI, et al. Luminescence imaging using radionuclides: a potential application in molecular imaging. Nucl Med Biol. 2011;38:321-329.

37. Thorek DL, Das S, Grimm J. Molecular imaging using nanoparticle quenchers of Cerenkov luminescence. Small. 2014;10:3729-3734. 